
UNDER CONTRACT DE-AC02-76CH03073

PPPL-3872

PPPL-3872

UC-70

Diagnostics for the National Compact Stellarator Experiment

by

B.C. Stratton, D. Johnson, R. Feder, E. Fredrickson, H. Neilson,

H. Takahashi, M. Zarnstorff, M. Cole, P. Goranson,

E. Lazarus, and B. Nelson

September 2003

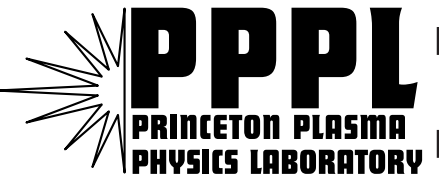

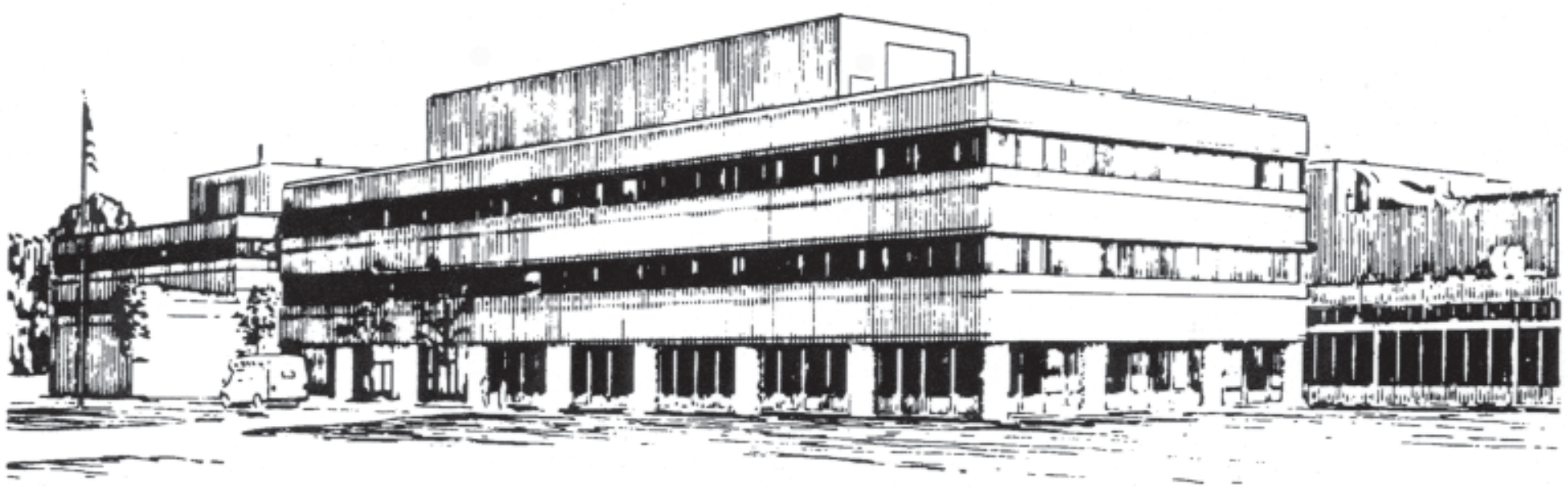

PRINCETON PLASMA PHYSICS LABORATORY PRINCETON UNIVERSITY, PRINCETON, NEW JERSEY 


\section{PPPL Reports Disclaimer}

This report was prepared as an account of work sponsored by an agency of the United States Government. Neither the United States Government nor any agency thereof, nor any of their employees, makes any warranty, express or implied, or assumes any legal liability or responsibility for the accuracy, completeness, or usefulness of any information, apparatus, product, or process disclosed, or represents that its use would not infringe privately owned rights. Reference herein to any specific commercial product, process, or service by trade name, trademark, manufacturer, or otherwise, does not necessarily constitute or imply its endorsement, recommendation, or favoring by the United States Government or any agency thereof. The views and opinions of authors expressed herein do not necessarily state or reflect those of the United States Government or any agency thereof.

\section{Availability}

This report is posted on the U.S. Department of Energy's Princeton Plasma Physics Laboratory Publications and Reports web site in Fiscal Year 2003. The home page for PPPL Reports and Publications is: http://www.pppl.gov/pub_report/

DOE and DOE Contractors can obtain copies of this report from:

U.S. Department of Energy

Office of Scientific and Technical Information

DOE Technical Information Services (DTIS)

P.O. Box 62

Oak Ridge, TN 37831

Telephone: (865) 576-8401

Fax: (865) 576-5728

Email: reports@adonis.osti.gov

This report is available to the general public from:

National Technical Information Service

U.S. Department of Commerce

5285 Port Royal Road

Springfield, VA 22161

Telephone: $1-800-553-6847$ or

(703) $605-6000$

Fax: (703) 321-8547

Internet: http://www.ntis.gov/ordering.htm 


\title{
Diagnostics for the National Compact Stellarator Experiment
}

\author{
B. C. Stratton, D. Johnson, R. Feder, E. Fredrickson, \\ H. Neilson, H. Takahashi, and M. Zarnstorff \\ Princeton Plasma Physics Laboratory, Princeton, New Jersey, USA \\ M. Cole, P. Goranson, E. Lazarus, and B. Nelson \\ Oak Ridge National Laboratory, Oak Ridge, Tennessee, USA
}

\begin{abstract}
The status of planning of NCSX diagnostics is presented, with the emphasis on resolution of diagnostics access issues and on diagnostics required for the early phases of operation.

\section{Introduction}

The National Compact Stellarator Experiment (NCSX) will explore stellarator physics in quasi-axisymmetric plasmas at low aspect ratio (R/G飞4.4) and high $\square(\sim 4 \%)[1,2]$. NCSX is a three-period stellarator with the majority of the rotational transform provided by a set of 18 modular coils. A set of toroidal field, poloidal field, and trim coils will allow access to a wide range of equilibria. NCSX will have $\mathrm{R}=1.4 \mathrm{~m}$ and $\mathrm{B} \leq 2.0 \mathrm{~T}$, with pulse lengths up to one second. $3 \mathrm{MW}$ of neutral beam heating power will be implemented in early in the experimental program, providing the plasma heating and bootstrap current drive required for high $\square$ operation. Additional neutral beam power and radio-frequency heating may be added later. To provide good vacuum conditions, the vacuum vessel will be baked to $150 \mathrm{C}$ and the plasma facing components (PFCs) will be baked to $350 \mathrm{C}$.

NCSX will have a full complement of diagnostics implemented in phases to accommodate the goals of the research plan [3]. Table I shows the planned diagnostics and their implementation in each phase of the research plan. The goals of the short (one month) initial operation phase are to test the coils and vacuum systems by making a plasma with $\mathrm{I}_{\mathrm{p}}>25 \mathrm{kA}$. This phase is following by e-beam mapping of the vacuum field structure for several months. The diagnostics required for initial operation and vacuum field mapping are included in the NCSX construction project. The diagnostics required for the initial experiments phase (1.5 MW NBI) will be installed in a shutdown following vacuum field mapping. The goals of this phase (six months) include learning to control the plasma shape and position, debugging the magnetics diagnostics and equilibrium reconstruction technique, and assessment of global confinement. The primary NCSX mission is addressed in the longer phases of the program covering operation with $3 \mathrm{MW} \mathrm{NBI}$, high confinement and high- $\square$ operation, and long pulse operation.

This paper describes the current status of NCSX diagnostic planning, with emphasis on design of the vacuum vessel ports to ensure good diagnostic access and on diagnostics needed for the early stages of the research program.
\end{abstract}

\section{Modification of Vacuum Vessel Ports to Improve Diagnostic Access}

NCSX presents a challenge to diagnostic access because the vacuum vessel is entirely enclosed by a shell supporting the modular coils and by a cryostat that will contain liquid nitrogen to cool the modular coils. Port locations are restricted by the need to clear the modular 
Table I. Planned NCSX diagnostics and phased implementation.

\begin{tabular}{|c|c|}
\hline Research program phase/Measurement & Diagnostic technique \\
\hline \multicolumn{2}{|c|}{ 1. Initial Operation $(B=0.5 T$, room temperature $)$} \\
\hline$I_{p}$ & Rowgowski coil \\
\hline Wide-angle image of plasma/wall & Visible camera (1) \\
\hline \multicolumn{2}{|l|}{ 2. Initial Field Line Mapping (no plasma) } \\
\hline Vacuum flux surfaces & E-beam, fluorescent probe \& CCD camera \\
\hline \multicolumn{2}{|c|}{ 3. 1.5 MW Initial Experiments (1.5 MW NBI, B=1.2 T, cryogenics, minimal PFCs) } \\
\hline Boundary position and shape & \begin{tabular}{|l|l} 
Saddle loops, flux loops, B probes, 3-D EFIT \\
\end{tabular} \\
\hline Total stored energy & Diamagnetic loop \\
\hline Wide-angle image of plasma/wall & Visible cameras with filters (2) \\
\hline Core $\mathrm{T}_{\mathrm{e}}$ & $\begin{array}{l}\text { Basic Thomson scattering or filtered SXR diodes, } \\
\text { \& x-ray crystal spectrometer }\end{array}$ \\
\hline $\mathrm{n}_{\mathrm{e}}$ profile & FIR interferometer/polarimeter \\
\hline Core $\mathrm{T}_{\mathrm{i}}$ & X-ray crystal spectrometer \\
\hline Total $\mathrm{P}_{\mathrm{rad}}$ & Wide angle bolometer \\
\hline Low m,n MHD modes $(<100 \mathrm{kHz})$ & Compact soft x-ray arrays (8 20-channel arrays) \\
\hline Magnetic axis position & Compact soft x-ray arrays \& 3-D EFIT \\
\hline Impurity identification & Visible spectrometer \\
\hline $\mathrm{VB}, \mathrm{H}_{\square} \&$ carbon line emission & Visible filterscopes \\
\hline PFC temperature & Compact IR camera \\
\hline \multicolumn{2}{|c|}{ 4. 3 MW Heating (3 MW NBI, full PFCs, B=2.0 T, $350 \mathrm{C}$ bake) } \\
\hline $\mathrm{T}_{\mathrm{e}}$ profile & Full Thomson scattering system \\
\hline $\mathrm{T}_{\mathrm{i}}, \mathrm{v}_{\square}$ profiles & DNB \& CHERS \\
\hline Rotational transform profile & DNB \& MSE, FIR inter./polar., 3-D EFIT \\
\hline Higher m,n MHD modes & Additional soft $\mathrm{x}$-ray arrays (8 20-channel arrays) \\
\hline High-frequency MHD (<5 MHz) & High-frequency Mirnov coils \\
\hline Flux surface topology & Tangential SXR camera \\
\hline Impurity concentrations & Absolute VUV spectroscopy \\
\hline$Z_{\text {eff }}$ profile & Thomson scattering detector system \\
\hline $\mathrm{P}_{\mathrm{rad}}$ profile & Core bolometer array \\
\hline Fast ion loss & Fast ion loss probe, IR camera \\
\hline Ion energy distribution & Neutral particle analyzer \\
\hline Neutron flux & Epithermal neutron detector \\
\hline SOL $\mathrm{n}_{\mathrm{e}}$ and $\mathrm{T}_{\mathrm{e}}$ & Movable Langmuir probe \\
\hline Edge neutral pressure & Fast pressure gauges \\
\hline \multicolumn{2}{|c|}{ 5. Confinement \& $\square$ push (3 MW NBI \& $6 M W N B I$ or RF, divertor) } \\
\hline Core $\mathrm{n}_{\mathrm{e}}$ fluctuations & Fluctuation diagnostic (HIBP and/or BES) \\
\hline Core helium density profile & DNB \& He CHERS \\
\hline Divertor $\mathrm{P}_{\mathrm{rad}}$ profile & Divertor bolometer arrays \\
\hline Divertor plate temperature & Fast IR camera \& thermocouples \\
\hline Target $\mathrm{T}_{\mathrm{e}} \& \mathrm{n}_{\mathrm{e}}$ & Plate-mounted Langmuir probes \\
\hline Divertor recycling & Divertor filtered 1-D CCD camera \\
\hline Divertor Impurity concentrations \& flows & Divertor VUV spectroscopy \\
\hline \multicolumn{2}{|c|}{ 6. Long pulse (Existing heating \& 3 MW long pulse NBI or RF) } \\
\hline Divertor $\mathrm{T}_{\mathrm{e}} \& \mathrm{n}_{\mathrm{e}}$ profiles & Divertor Thomson scattering \\
\hline
\end{tabular}




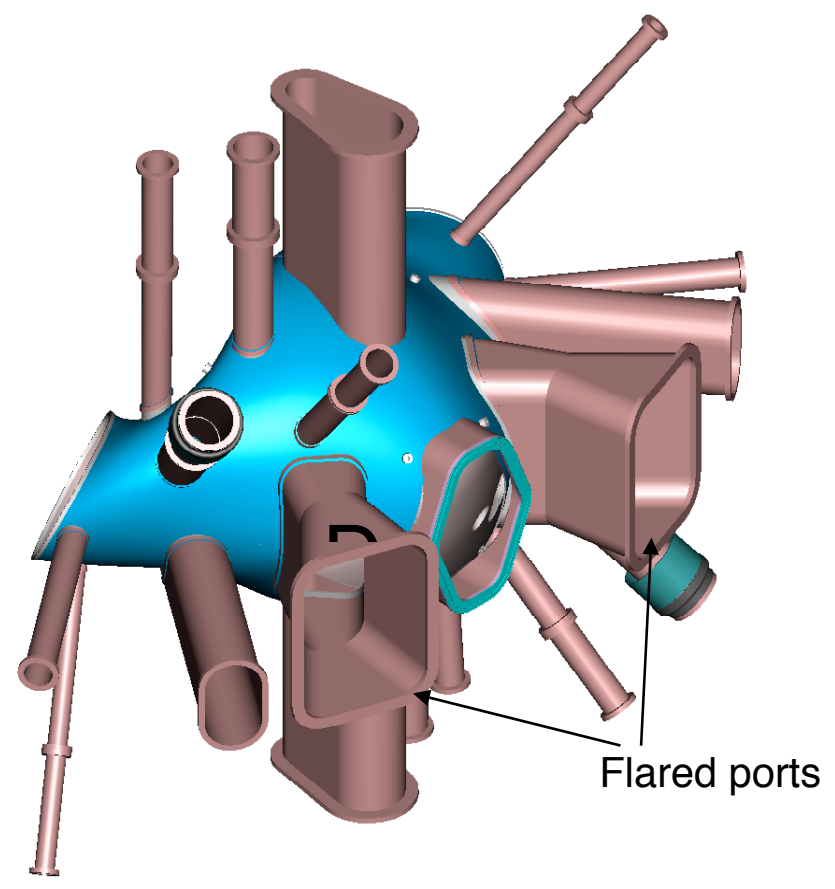

Fig. 1. View of one NCSX vacuum vessel period showing flared midplane ports.

and toroidal field coils. As a result, diagnostic ports are being carefully planned to insure the needed access. Figure 1 shows one period of the present vacuum vessel design. There are 87 ports with two of them reserved for the two initial neutral beam injectors. This number is adequate to accommodate the planned diagnostic set, with some ports left vacant for other uses or for future diagnostics.

Six of the large midplane ports have been optimized to provide the needed field-of-view for diagnostics such as charge exchange recombination spectroscopy (CHERS), Motional Stark Effect (MSE), and Thomson Scattering. This was done by flaring the ports in both the horizontal and vertical directions, as shown in Fig. 1. Because the heating neutral beams are wide and are injected tangentially, a narrow diagnostic neutral beam (DNB) will be required to insure good spatial resolution for the CHERS and MSE diagnostics. To optimize radial resolution, the DNB trajectory will be nearly tangential to the flux surfaces where the beam intersects the CHERS/MSE sightlines, as shown in Fig. 2. The expected radial resolution varies from $\sim 1 \mathrm{~cm}$ at the outer plasma edge to $\sim 2 \mathrm{~cm}$ at the inner edge, sufficient to provide detailed radial profiles. This arrangement also provides the MSE diagnostic with sufficient Doppler shift of the beam $\mathrm{H}_{\square}$ emission away from the edge emission. Figure 2 shows how the flared diagnostic ports accommodate large-diameter CHERS/MSE viewing optics. Large-diameter Thomson Scattering optics will view a vertically-injected laser beam through a similar port at a different location on the vacuum vessel. For the CHERS/MSE and Thomson scattering diagnostics, the large-aperture optics possible with the flared port provide twice the throughput of the largest optics possible in a straight port. Compared to the cost of a higher power DNB or laser, this is a cost-effective way to 


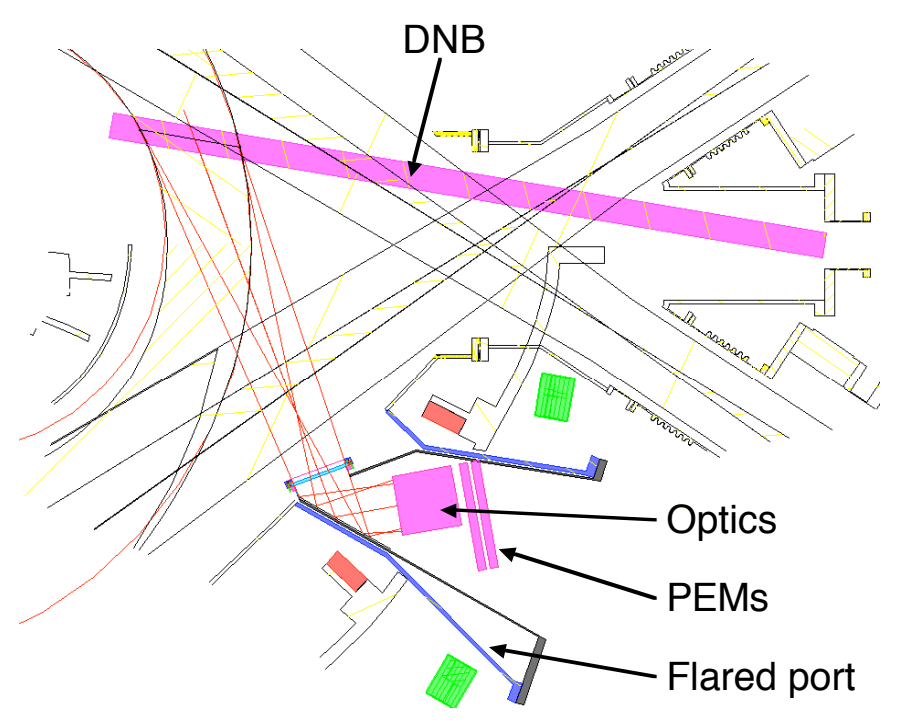

Fig. 2. Plan view of flared port showing high-throughput CHERS/MSE optics and DNB

increase the signals for these diagnostics. Other diagnostics, such as the neutral particle analyzer and beam emission spectroscopy, will also benefit from these flared ports.

In an effort to optimize diagnostic access, we are exploring also the feasibility of similar flaring of the smaller oval ports adjacent to these large ports and increasing the diameters of some of the smaller circular cross-section ports.

\section{Equilibrium Magnetics}

A large set of magnetic field sensors will be required to accurately reconstruct the plasma equilibrium and for plasma control. These sensors will include saddle coils on the outside of the vessel, B-dot probes on the inside of the vessel, Rogowski loops, diamagnetic loops, and flux loops co-wound with all of the coils. Modeling is underway to determine the number and optimum locations for each sensor type; a preliminary estimate is that a total of 300-400 sensors will be required. The saddle coils, internal probes, and co-wound loops will be fabricated from mineral-insulated cable to insure reliability. Installation of these sensors presents several challenges. The external saddle loops must be installed on the external surface of the vacuum vessel during machine assembly because they will be trapped between the vessel and the modular coil shells. The challenge for the internal probes is that little space (1-2 $\mathrm{cm}$ or less) is available between the inside surface of the vessel and the vessel PFC liner in many places. However, compact coils with radial extent of $0.5 \mathrm{~cm}$ are possible [4]. Design of these coils will start when the internal space envelopes are known following completion of the vessel design. The co-wound loops on the coils will be installed during coil construction.

\section{Vacuum Field Mapping}

The vacuum field structure will be measured early in the research program using an electronbeam field line mapping diagnostic, as has been done on other stellarators. It should be possible to use the trim coils to eliminate or reduce the size of low order islands arising from errors in 
machine assembly. Modeling is underway to establish the measurement requirements for this diagnostic. An initial result of this study is that the best spatial resolution is obtained by putting the fluorescent rod or screen at the oblate $(\mathrm{v}=1 / 2)$ cross section because the flux surface expansion is largest there. This study will determine whether or not the standard technique of CCD camera imaging of the visible light emitted when the circulating electron beam strikes a fluorescent rod or mesh screen provides adequate spatial resolution and has sufficient time resolution to be able to follow changes in the field due to changes in the coil currents. If not, development of a more efficient light collection technique using fiber optics may be required. A design goal is that deployment of the diagnostic be possible without breaking machine vacuum.

\section{Compact Soft X-Ray Arrays}

MHD mode structure will be studied using data from a set of soft x-ray (SXR) diode arrays in addition to data from high-frequency Mirnov coils, as has been done on W7-AS [5] and LHD [6]. The SXR array data should also be useful in efforts to eliminate low-order islands using the trim coils. Design goals for the NCSX SXR arrays are sufficient spatial resolution and plasma coverage to allow reliable tomographic reconstructions and high time resolution $(>100 \mathrm{kHz})$. The initial installation will have 160 channels (8 arrays of 20 channels each) with an additional 160 channels to be added later. Spatial resolution in the plasma core of $\sim 2 \mathrm{~cm}$ can be obtained with nearly complete plasma coverage with 160 channels if the arrays are located near the oblate plasma cross section. Figure 3 shows the sightlines from one 20 -channel SXR array with $\sim 2 \mathrm{~cm}$ resolution in the oblate cross section; the other arrays would be spaced roughly equally around this poloidal cross section. An additional 160 channels should allow $\sim 1 \mathrm{~cm}$ resolution to be achieved. The baseline plan is to place compact arrays inside the vacuum vessel as is planned for the W7-X SXR arrays [7]. To obtain $\sim 1 \mathrm{~cm}$ spatial resolution in NCSX, the photodiode array (IRD AXUV-20EL) must be placed $4 \mathrm{~cm}$ from the entrance slit. Allowing for the additional depth required for the chip socket, wiring and an enclosure yields a minimum required radial depth of $6 \mathrm{~cm}$. To obtain high frequency response, the preamps must be placed in a secondary vacuum enclosure adjacent to the photodiode arrays. Active cooling (water or gas) is required to prevent damage to the arrays during baking. It appears that the required the radial space is

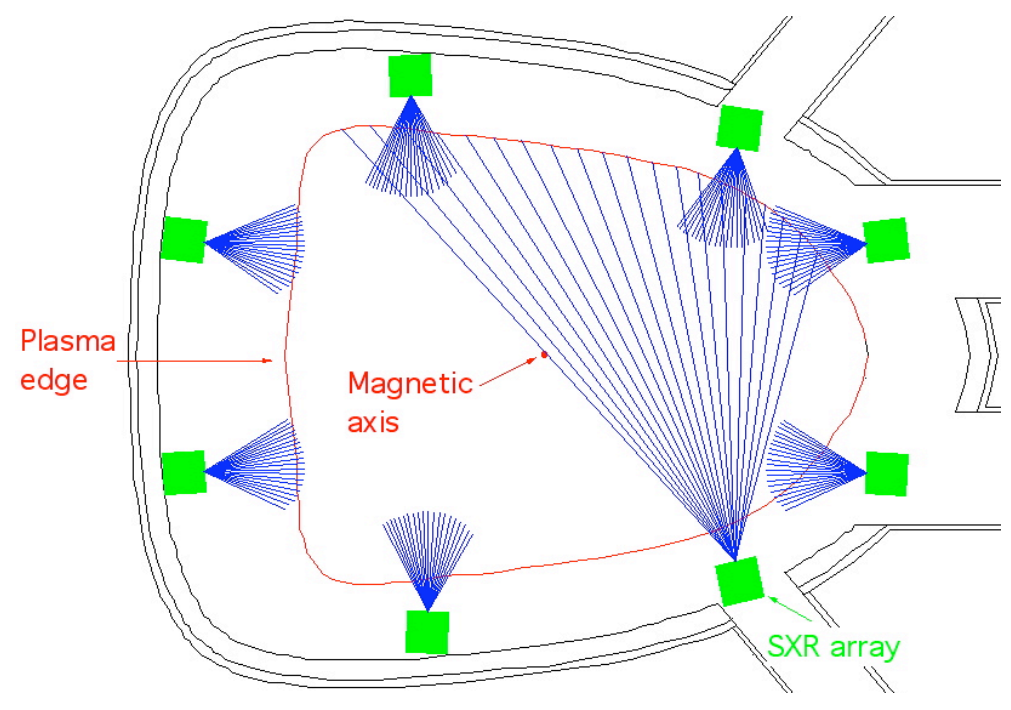

Fig. 4. Sightlines of 20 channel soft $x$-ray arrays with $\sim 2 \mathrm{~cm}$ radial resolution in plasma core. 
available inside the vessel in the vicinity of the oblate cross section. The available space is affected by the design of the welded vacuum vessel joints and the space required for the ICRF antennas at the oblate cross sections. We are working to make this space as large as possible.

An interesting alternative to use of photodiodes in vacuum is being explored by the Johns Hopkins University spectroscopy group [8]. An array of CsI:Tl scintillators converts the SXR emission to visible light, which is transmitted via fiber optics to avalanche photodiode or photomultiplier detectors located outside the vacuum vessel. This eliminates the need for placing the preamplifiers in vacuum and for active cooling during baking. Laboratory testing indicates that columnar CsI:Tl scintillators have the required quantum efficiency and rapid time response. A prototype array of this type will be tested on the CDX-U and NSTX devices in the coming year. If the results are satisfactory, this approach could be adopted for the NCSX SXR arrays.

\section{Conclusion}

NCSX operation will start in 2007. The limited set of diagnostics required for initial operation must be installed by first plasma, and preparation for the diagnostics required for the next phases of the research program must be well underway by then. To achieve this, we will start assembling the NCSX diagnostics team in 2004. Because NCSX is structured as a collaborative project, this team will include members from a variety of US and international fusion laboratories.

Acknowledgments

This research was supported by the US Department of Energy under Contract No. DE-AC02$76 \mathrm{CH} 03073$ with the Princeton Plasma Physics Laboratory and Contract No. DE-AC05-00OR22725 with the Oak Ridge National Laboratory.

\section{References}

1. G. H. Neilson et al., Proceedings of the $19^{\text {th }}$ IAEA Fusion Energy Conference (Lyon, France, October 2002). Paper no. IAEA-CN-94/IC-1.

2. M. Zarnstorff et al., this conference.

3. D. Johnson, et al., Rev. Sci. Instrum. 74 (2003) 1787.

4. T. Bolzonella, et al., Rev. Sci. Instrum. 74 (2003) 1554.

5. A. Weller et al., Rev. Sci. Instrum. 70 (1999) 484.

6. S. Ohdachi et al., Rev. Sci. Instrum. 72 (2001) 727.

7. S. Klose et al., in Advanced Diagnostics for Magnetic and Inertial Fusion, edited by Stott, et al. (Kluwer Academic/Plenum Publishers, New York 2002), pp. 229-232.

8. L. -Delgado Aparicio, et al., submitted to Review of Scientific Instruments. 


\section{External Distribution}

Plasma Research Laboratory, Australian National University, Australia

Professor I.R. Jones, Flinders University, Australia

Professor João Canalle, Instituto de Fisica DEQ/IF - UERJ, Brazil

Mr. Gerson O. Ludwig, Instituto Nacional de Pesquisas, Brazil

Dr. P.H. Sakanaka, Instituto Fisica, Brazil

The Librarian, Culham Laboratory, England

Mrs. S.A. Hutchinson, JET Library, England

Professor M.N. Bussac, Ecole Polytechnique, France

Librarian, Max-Planck-Institut für Plasmaphysik, Germany

Jolan Moldvai, Reports Library, Hungarian Academy of Sciences, Central Research Institute for Physics, Hungary

Dr. P. Kaw, Institute for Plasma Research, India

Ms. P.J. Pathak, Librarian, Institute for Plasma Research, India

Ms. Clelia De Palo, Associazione EURATOM-ENEA, Italy

Dr. G. Grosso, Instituto di Fisica del Plasma, Italy

Librarian, Naka Fusion Research Establishment, JAERI, Japan

Library, Laboratory for Complex Energy Processes, Institute for Advanced Study, Kyoto University, Japan

Research Information Center, National Institute for Fusion Science, Japan

Dr. O. Mitarai, Kyushu Tokai University, Japan

Dr. Jiangang Li, Institute of Plasma Physics, Chinese Academy of Sciences, People's Republic of China

Professor Yuping Huo, School of Physical Science and Technology, People's Republic of China

Library, Academia Sinica, Institute of Plasma Physics, People's Republic of China

Librarian, Institute of Physics, Chinese Academy of Sciences, People's Republic of China

Dr. S. Mirnov, TRINITI, Troitsk, Russian Federation, Russia

Dr. V.S. Strelkov, Kurchatov Institute, Russian Federation, Russia

Professor Peter Lukac, Katedra Fyziky Plazmy MFF UK, Mlynska dolina F-2, Komenskeho Univerzita, SK-842 15 Bratislava, Slovakia

Dr. G.S. Lee, Korea Basic Science Institute, South Korea

Institute for Plasma Research, University of Maryland, USA

Librarian, Fusion Energy Division, Oak Ridge National Laboratory, USA

Librarian, Institute of Fusion Studies, University of Texas, USA

Librarian, Magnetic Fusion Program, Lawrence Livermore National Laboratory, USA

Library, General Atomics, USA

Plasma Physics Group, Fusion Energy Research Program, University of California at San Diego, USA

Plasma Physics Library, Columbia University, USA

Alkesh Punjabi, Center for Fusion Research and Training, Hampton University, USA

Dr. W.M. Stacey, Fusion Research Center, Georgia Institute of Technology, USA

Dr. John Willis, U.S. Department of Energy, Office of Fusion Energy Sciences, USA

Mr. Paul H. Wright, Indianapolis, Indiana, USA 
The Princeton Plasma Physics Laboratory is operated by Princeton University under contract with the U.S. Department of Energy.

\author{
Information Services \\ Princeton Plasma Physics Laboratory \\ P.O. Box 451 \\ Princeton, NJ 08543
}

Phone: 609-243-2750

Fax: 609-243-2751

e-mail: pppl_info@pppl.gov

Internet Address: http://www.pppl.gov 